\title{
Excretion of Catecholamine in Urine by Infants and Children with Cyanotic Congenital Heart Disease
}

\author{
Gordon M. Folger, Jr. ${ }^{[37]}$, AND Joseph G. Hollowell \\ Department of Pediatrics, Medical College of Georgia, Eugene Talmadge Memorial Hospital, Augusta, Georgia, USA
}

\section{Extract}

Catecholamine excretion in urine was assessed in a group of unstressed acyanotic infants and children and in a comparable group of children with cyanotic forms of congenital heart disease. Twenty-four hour excretion of epinephrine (E), norepineph(NE), 3-methoxy-4-hydroxymandelic acid (VMA), dopamine (DA), and metanephrine and normetanephrine combined $(\mathrm{MN}+\mathrm{NMN})$ was measured in all individuals. Significant elevations of DA were found in the cyanotic patients when compared with the controls, with control values being $8.53 \mu \mathrm{g} / \mathrm{kg} / 24 \mathrm{hr}$ compared with values in the cyanotic subjects of $17.09 \mu \mathrm{g} / \mathrm{kg} / 24 \mathrm{hr}(P<0.001)$. Likewise, MN + NMN values were significantly elevated in the cyanotic subjects, control values being 43.25 $\mu \mathrm{g} / \mathrm{kg} / 24 \mathrm{hr}$ and those of the cyanotic patients $90.51 \mu \mathrm{g} / \mathrm{kg} / 24 \mathrm{hr}(P<0.025)$. The $\mathrm{E}, \mathrm{NE}$, and VMA values showed no significant differences, although in the cyanotic patients the tendency was of elevation over control values. The presence of elevated amounts of DA in the urines of cyanotic individuals indicates an increased release of this neurohormone in the stressed individuals. The presence of elevated amounts of $\mathrm{MN}+\mathrm{NMN}$ in the urine of cyanotic patients further supports this finding and indicates that secretion of $\mathrm{E}$ and $\mathrm{NE}$ is in actuality also increased.

\section{Speculation}

Hypoxemia as the only demonstrable stressful stimulus is capable of eliciting an increase in the secretion of the catecholamines. This increase in circulating neurohormones and their attendant pharmacologic influences may seriously affect the course of the child with hypoxemia secondary to cyanotic forms of congenital heart disease by promoting the occurrence of metabolic acidemia and causing a decrease in pulmonary blood flow.

\section{Introduction}

The use of $\beta$-adrenergic blocking agents to exert a negative inotropic effect on the myocardium currently provides one basis of therapy for certain cardiac conditions, principally those having muscular outflow tract obstruction involving either ventricle $[4,7,8,12,14$,
16, 22]. Those in which cyanosis is produced as a consequence of the obstruction constitute a significant and increasing number so treated. Catecholamine elaboration in this group of individuals in whom detrimental effects are implied by such therapy has not been adequately evaluated. 
The current study was undertaken to measure excretion of catecholamines in the urine of normal infants and children as well as a group of individuals with cyanotic forms of congenital cardiac abnormalities in an effort to assess the influence of a chronically stressful situation such as cardiac-induced hypoxemia on catecholamine excretion.

\section{Materials and Methods}

The patients were grouped by age: group $I$ contained those under 1 year of age; group $I I$, those between 1 and 5 years of age; and group III, those over 5 years of age. The controls, consisting of 23 noncyanotic patients, ranged in age from 13 days to 14 years. All of these patients were hospitalized at the time of, and were randomly selected for, the study. Five children were admitted to the study without any known condition, whereas the remaining eighteen had been electively admitted for study of, or treatment of, conditions not considered to stimulate the secretion of catecholamines. Six patients had forms of acyanotic heart disease, two had rheumatic valvular disease, one was under investigation for recurrent atrial tachycardia, and one each had ventricular septal defect, pulmonary arterial stenosis, and coarctation of the aorta. None was in heart failure and none received drugs with the exception of penicillin.

The cyanotic group of 25 children ranged from 3 days to 10 years of age and were selected consecutively on the basis of hospital admission for evaluation of their problem. More cyanotic children than controls fell into the neonatal age range, and these children all tended to be smaller than their noncyanotic controls. There were 13 patients with the tetralogy of Fallot, 4 with transposition of the great vessels, one each with tricuspid atresia, pulmonary atresia, and total anomalous drainage of the pulmonary veins, and 5 with complex defects. None was considered clinically to be in heart failure when studied and none received drugs excepting six infants taking digoxin for decompensation suspected and controlled before the study.

Studies were carried out on 24-hr urine specimens containing sufficient $6 \mathrm{~N} \mathrm{HCl}$ to keep the $\mathrm{pH}$ below 1.0. Samples were kept on ice during the collection periods and were stored frozen until analyzed. The patients and control subjects were hospitalized before and during collection period and were fed a standardized diet containing milk, eggs, and carbohydrates beginning $24 \mathrm{hr}$ before the test urine was obtained. All other foods were omitted to avoid any possible exogenous source of organic amines and acids. Urine collections on neonates were all carried out with the individ- ual housed in an Isolette incubator with Servo control. Older infants and children underwent collection at standard ward or nursery temperatures. Body temperatures were never found to be below normal ranges immediately before or during a collection period. Each urine sample was studied to determine the amount of the substance in question in respect to amount per 24 hr (micrograms per $24 \mathrm{hr}$ ) as well as correction for body weight (micrograms per kilogram per $24 \mathrm{hr}$ ).

In an effort to counteract any possible effect of hospitalization on catecholamine excretion, all children old enough to do so were free to participate in the usual ward activities with no limitations, and parents were encouraged to be present as much as possible.

Norepinephrine (NE) and epinephrine (E) were determined by a modification of the fluorimetric method of Von Euler and Floding [29], using iodine as the oxidant. Fluorescence of solutions was measured with a Turner fluorimeter model 110 [33], using, for excitation, a narrow band interference filter with peak transmission at $395 \mathrm{~m} \mu$ and, for emission, Corning filter no. 3-69. Dopamine (DA) was measured by the fluorimetric method of Carlsson and Waldeck [5], using Corning filter 7-37 for excitation and Corning filters 3-73 and 5-58 in combination for emission. The spectrophotometric method of Pisano et al. [25] was used to determine 3-methoxy-4-hydroxymandelic acid (VMA). The two dimensional paper chromatographic method of Armstrong et al. [1] for phenolic acids was used to retest most of the urine samples for VMA, especially those with elevated amounts. No significant changes were encountered at retest. The method of Pisano [24] was used to measure combined metanephrine and normetanephrine (MN + NMN) in urine after their oxidation to vanillin.

\section{Results}

\section{Table I}

In that differences encountered between excretion values per $24 \mathrm{hr}$ and values when corrected for weight were insignificant excepting those noted in the text, only those reported in micrograms per kilogram per $24 \mathrm{hr}$ appear in Table I and in the following illustrations.

\section{Dopamine (Fig. 1)}

The values for DA both in micrograms per $24 \mathrm{hr}$ and micrograms per kilogram per $24 \mathrm{hr}$ in the control patients compared favorably with those reported by Voorhess [30] and showed wide scatter. The DA excretion values for the cyanotic patients significantly 
Table I. Values for catecholamine ${ }^{1}$ excretion in urine

\begin{tabular}{|c|c|c|c|c|c|c|}
\hline \multirow{2}{*}{ Patients } & \multirow{2}{*}{$\mathrm{Wt}, \mathrm{kg}$} & \multicolumn{5}{|c|}{$\mu \mathrm{g} / \mathrm{kg} / 24 \mathrm{hr}$} \\
\hline & & $\mathrm{DA}$ & $\mathrm{NE}$ & $E$ & VMA & $\mathrm{MN}+\mathrm{NMN}$ \\
\hline \multicolumn{7}{|l|}{ Group I } \\
\hline \multicolumn{7}{|c|}{ Control (10 subjects) } \\
\hline Range & $1.95-9.1$ & $4.44-24.5$ & $0.99-11.30$ & $0.187-1.385$ & $117.1-781.0$ & $13.3-269.2$ \\
\hline Mean & 4.94 & 13.57 & 3.40 & 0.560 & 272.4 & 58.08 \\
\hline SD & \pm 2.02 & \pm 1.47 & \pm 0.96 & \pm 0.124 & \pm 71.3 & \pm 23.94 \\
\hline \multicolumn{7}{|c|}{ Cyanotic (11 subjects) } \\
\hline Range & $2.85-6.5$ & $13.80-54.63$ & $1.63-10.80$ & $0.107-1.450$ & $128.2-537.2$ & $52.1-163.1$ \\
\hline Mean & 4.11 & 25.12 & 4.37 & 0.650 & 256.4 & 95.14 \\
\hline SD & \pm 1.32 & \pm 13.43 & \pm 0.80 & \pm 0.138 & \pm 35.6 & \pm 14.69 \\
\hline Significance level & & $P<0.02$ & $P>0.10$ & $P>0.10$ & $P>0.10$ & $P<0.05$ \\
\hline \multicolumn{7}{|l|}{ Group II } \\
\hline \multicolumn{7}{|l|}{ Control (4 subjects) } \\
\hline Range & $9.1-17.6$ & $2.61-8.43$ & $1.16-1.80$ & $0.135-0.446$ & $101.5-233.5$ & $9.2-46.6$ \\
\hline Mean & 13.1 & 4.82 & 1.48 & 0.219 & 149.5 & 32.75 \\
\hline SD & \pm 3.30 & \pm 1.27 & \pm 0.16 & \pm 0.075 & \pm 29.1 & \pm 8.2 \\
\hline \multicolumn{7}{|c|}{ Cyanotic (8 subjects) } \\
\hline Range & $6.6-13.8$ & $5.67-27.66$ & $1.00-4.35$ & $0.129-0.550$ & $105.2-379.5$ & $44.1-209.3$ \\
\hline Mean & 9.9 & 12.33 & 2.89 & 0.293 & 212.7 & 103.55 \\
\hline SD & \pm 2.37 & \pm 2.63 & \pm 0.36 & \pm 0.050 & \pm 32.3 & \pm 21.47 \\
\hline Significance level & & $P<0.02$ & $P<0.01$ & $P>0.10$ & $P>0.10$ & $P<0.01$ \\
\hline \multicolumn{7}{|l|}{ Group III } \\
\hline \multicolumn{7}{|l|}{ Control (9 subjects) } \\
\hline Range & $16.5-48.8$ & $2.96-10.88$ & $0.65-2.28$ & $0.046-0.531$ & $56.3-241.9$ & $11.1-41.6$ \\
\hline Mean & 26.2 & 4.59 & 1.31 & 0.216 & 121.3 & 31.44 \\
\hline $\mathrm{sD}$ & \pm 9.15 & \pm 0.77 & \pm 0.18 & \pm 0.051 & \pm 17.3 & \pm 2.98 \\
\hline \multicolumn{7}{|c|}{ Gyanotic (6 subjects) } \\
\hline Range & $11.3-26.2$ & $2.70-13.58$ & $0.44-1.97$ & $0.049-0.794$ & $116.6-271.7$ & $43.5-106.7$ \\
\hline Mean & 20.4 & 8.69 & 1.50 & 0.328 & 161.8 & 64.63 \\
\hline $\mathrm{SD}$ & \pm 4.78 & \pm 1.71 & \pm 0.24 & \pm 0.111 & \pm 23.1 & \pm 10.12 \\
\hline Significance level & & $P<0.05$ & $P>0.10$ & $P>0.10$ & $P>0.10$ & $P<0.005$ \\
\hline \multicolumn{7}{|c|}{ Total acyanotic (23 subjects) } \\
\hline Range & $1.95-48.8$ & $2.61-24.5$ & $0.65-11.30$ & $0.046-1.385$ & $56.3-781.0$ & $9.2-269.2$ \\
\hline Mean & 14.29 & 8.53 & 2.25 & 0.366 & 191.9 & 43.25 \\
\hline SD & \pm 11.8 & \pm 0.62 & \pm 0.47 & \pm 0.068 & \pm 34.6 & \pm 10.61 \\
\hline \multicolumn{7}{|c|}{ Total cyanotic (25 subjects) } \\
\hline Range & $2.85-26.2$ & $2.70-54.63$ & $0.44-10.80$ & $0.049-1.450$ & $105.2-537.2$ & $43.5-209.3$ \\
\hline Mean & 9.9 & 17.09 & 3.21 & 0.458 & 219.71 & 90.51 \\
\hline $\mathrm{SD}$ & \pm 7.01 & \pm 1.81 & \pm 0.43 & \pm 0.074 & \pm 21.9 & \pm 9.85 \\
\hline Significance level & & $P<0.001$ & $P>0.10$ & $P>0.10$ & $P>0.10$ & $P<0.005$ \\
\hline
\end{tabular}

${ }_{1}$ DA: Dopamine. NE: Norepinephrine. E: Epinephrine. VMA : 3-Methoxy-4-hydroxymandelic acid. MN + NMN : Metanephrine and normetanephrine combined.

exceeded those of the control group for all ages when calculated in micrograms per kilogram per $24 \mathrm{hr}$. When expressed in micrograms per $24 \mathrm{hr}$, the differences were significant for groups $I(P<0.02)$ and $I I$ $(P<0.01)$ and for the total group $(P<0.01)$, but the difference was not significant for group III $(P>0.10)$.

\section{Norepinephrine (Fig. 2)}

The excretion of NE in a 24-hr period by controls compared closely with those previously reported [30]. When calculated for body weight, the control values also compared well, with the exception of one unexplainably high value in group $I(11.30 \mu \mathrm{g} / \mathrm{kg} / 24 \mathrm{hr}$; the next highest value in this group was $4.4 \mathrm{I} \mu \mathrm{g} / \mathrm{kg} / 24$ $\mathrm{hr}$. As seen in subsequent figures, this child also had values exceeding the other controls in respect to $\mathrm{E}$, MN + NMN, and VMA). Comparison of the control values with the values in the cyanotic patients revealed a significant difference only in group $I I$, whether calculated in micrograms per $24 \mathrm{hr}(P<0.02)$ or in micrograms per kilogram per $24 \mathrm{hr}(P<0.01)$, although the directional shift indicates higher excretions for both groups $I$ and $I I$ in respect to the cyanotic individuals. 


\section{Epinephrine (Fig. 3)}

Control E excretion values also correlated well with those previously reported [30]. No statistically significant difference between the cyanotic and control subjects in any single group or in the total group was found. The trend, however, was for somewhat higher excretion values in the cyanotic patients in all three groups.

\section{3-Methoxy-4-hydroxymandelic Acid (Fig. 4)}

Values for excretion of this metabolite in the entire control series slightly exceeded those reported previously [30] and, as with $\mathrm{E}$ excretion, no significant difference between the control and cyanotic patients was detectable. Similar to the results for $\mathrm{E}$ excretion, there

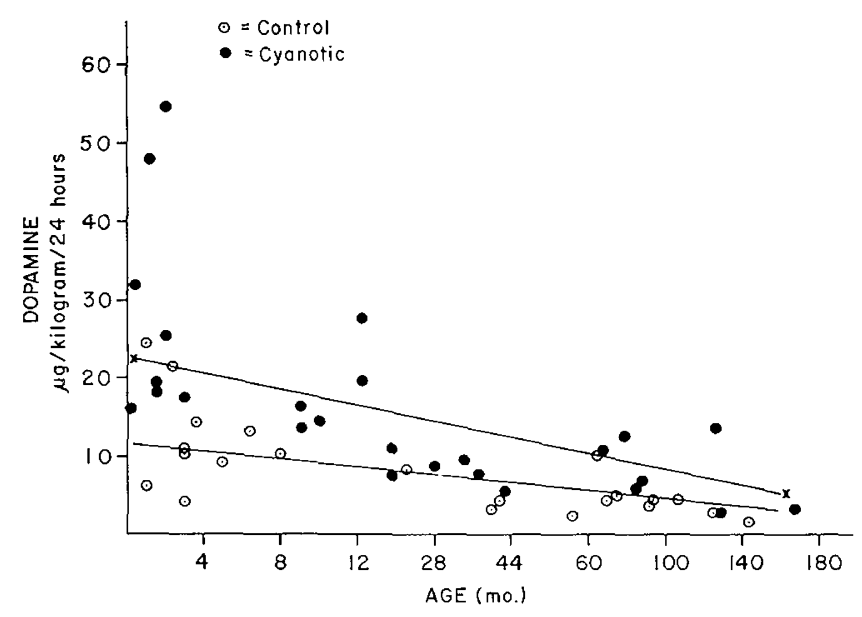

Fig. 1. Scattergram depicting excretion in urine of dopamine in micrograms per kilogram per $24 \mathrm{hr}$. The regression line $\times \longrightarrow$ corresponds to the cyanotic subjects.

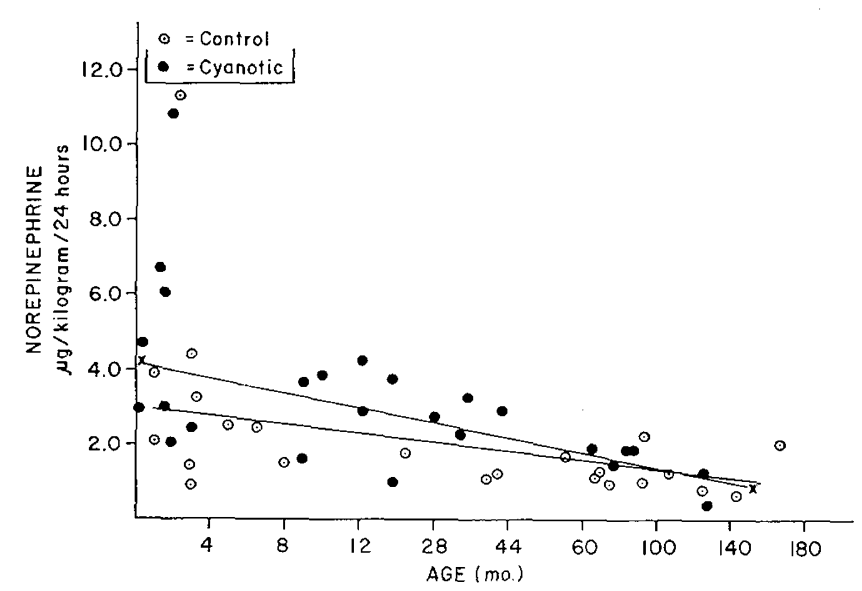

Fig. 2. Scattergram depicting excretion in urine of norepinephrine in micrograms per kilogram per $24 \mathrm{hr}$. The regression line $\times \longrightarrow \times$ corresponds to the cyanotic subjects.

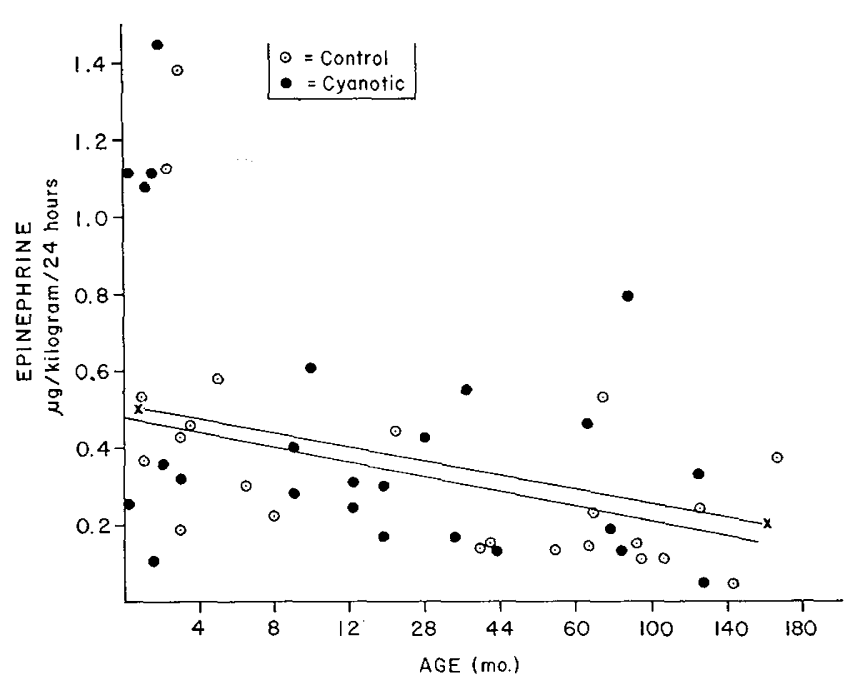

Fig. 3. Scattergram depicting excretion of epinephrine in urine in micrograms per kilogram per $24 \mathrm{hr}$. The regression line $x-X$ corresponds to the cyanotic subjects.

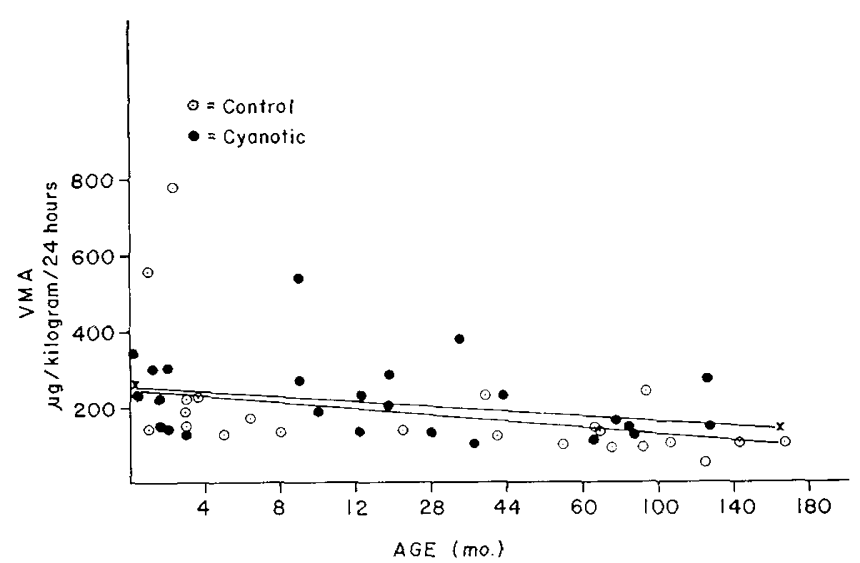

Fig. 4. Scattergram depicting excretion of VMA in urine in micrograms per kilogram per $24 \mathrm{hr}$. The regression line $\times-\times$ corresponds to the cyanotic subjects.

was a tendency toward increased VMA excretion in the cyanotic individuals in all three groups.

Metanephrine and Normetanephrine Combined (Fig.

5)

No data, in comparable groups, for the excretion values for these substances have, to our knowledge, been reported. Significant differences in excretion between control and cyanotic patients were present in all three groups and in the total series when calculated as micrograms per $24 \mathrm{hr}$ as well as when corrected for body weight.

\section{Discussion}

Two major alterations in the excretion pattern of the amines studied are apparent. One of these is the pres- 
ence of significantly elevated amounts of DA in the urine of the cyanotic patients. The other is the equally impressive increase in the amounts of MN + NMN exreted by these individuals. The meaning of these alterations in excretion of these amines is difficult to assess. However, with significant elevations in excretion in urine of both the immediate precursor (DA) as well as the principle metabolites of $\mathrm{E}$ and $\mathrm{NE}$ as a result of $O$-methylation $(\mathrm{MN}+\mathrm{NMN})$ [31, 32], it seems probable that endogenous secretion of these neurohormones was also elevated as indicated by directional changes favoring the cyanotic group even though they were not present in statistically significant increased amounts in the urine. It is noteworthy that similar excretion patterns have been reported by Lees [20] in cyanotic children, including failure of VMA elevation in the urine of these individuals. With these findings, we believe that there is sufficient evidence to suggest the elevation of physiologically active $\mathrm{E}$ and $\mathrm{NE}$ in the cyanotic subjects.

Nearly all of the E and NE normally formed in the body is metabolized and excreted as $O$-methylated or deaminated products. It is now accepted that most of the VMA arises from the deamination of NE by monoamine oxidase (MAO) within the sympathetic nerves followed by $O$-methylation outside the nerves [2]. Monoamine oxidase has no apparent role in the physiologic inactivation of $\mathrm{E}$ or NE [32]. Thus, the VMA in the urine likely represents the amount of NE produced and metabolized before causing any physiologic effect. Its measurement in the urine, then, gives an index of catecholamine synthesis but provides little information about the functional activity of the sympathetic nervous system. The NMN, on the other hand, largely represents the amount of physiologically active or free NE that has been discharged from the sympathetic nerves and acted upon by catechol-O-methyl transferase [2]. Thus, when NE is released onto receptors, the principle mode of inactivation is enzymatic $O$-methylation to form NMN. Indeed, Krakoff and co-workers [19] have used the urinary levels of the $O$-methylated amines as a measure of the amount of physiologically active NE released in the experimental animal, and, thus, in contrast to VMA, their measurement may be used as an index of functional activity of the sympathetic nervous system. Metanephrine and NMN are also major urinary metabolites of parenterally administered $\mathrm{E}$ and $\mathrm{NE}$, although significant amounts of VMA are produced $[3,18]$.

Monoamine oxidase inhibition enhances the excretion of free and conjugated monoamines such as the

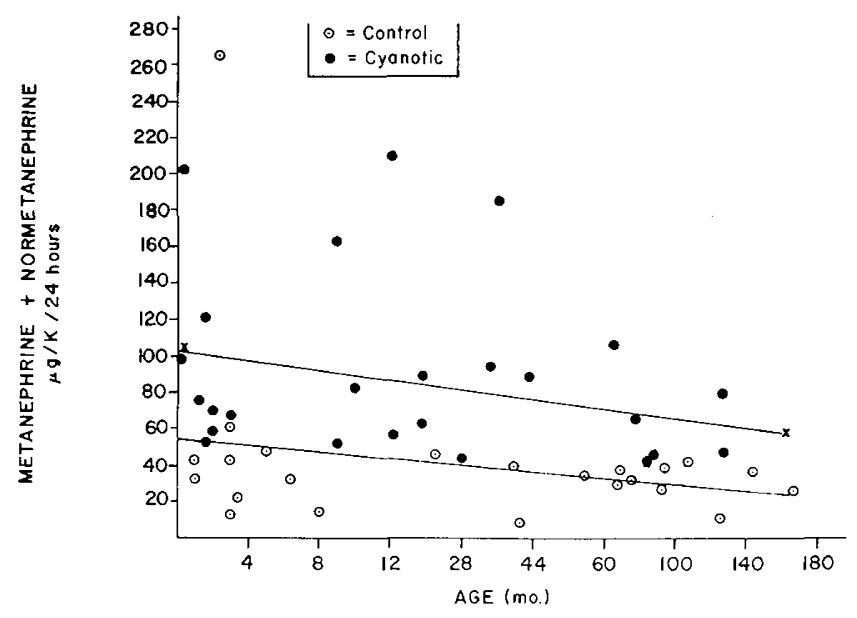

Fig. 5. Scattergram depicting excretion in urine of metanephrine and normetanephrine in micrograms per kilogram per 24 hr. The regression line $\times-\times$ corresponds to the cyanotic subjects.

$O$-methylated and nonmethylated catecholamines and diminishes the elimination of deaminated products such as VMA [26]. It would seem a possibility that MAO inhibition could have occurred intrinsically in the cyanotic subjects, resulting in the excretion patterns observed, although no data are available to support this hypothesis and it must, thus, remain conjectural.

With each of the foregoing possibilities, there is implied the presence of increased amounts of physiologically active $\mathrm{E}$ and $\mathrm{NE}$ as well as the demonstrated elevation of $\mathrm{DA}$ in the hypoxemic patients.

Although it is not the purpose of this study to investigate functional disturbances related to the catecholamines, the possible significance of the increase in these substances in the cyanotic individual deserves comment. It seems apparent that the positive inotropic myocardial effects of $\mathrm{E}$ and to less extent $\mathrm{NE}$ as well as those of DA $[13,23]$ may be enhanced by the presence of elevated amounts of these amines in individuals having reduced pulmonary blood flow and, thus, hypoxemia as a result of forms of muscular outflow tract obstruction from either ventricle $[4,16,22]$. These specific individuals may be affected most adversely by this dynamic increase in the degree of ventricular outflow obstruction by even greater reduction of their pulmonary blood flow and worsening of their condition, with the result being a further increase in hypoxemia.

Furthermore, the presence of these substances in increased amounts in individuals with hypoxemia secondary to nonobstructive as well as obstructive forms of cyanotic heart malformations may have a second 
profound effect by virtue of their recognized ability to increase tissue oxygen consumption [21]. The metabolic effect of such an alteration, especially when there is oxygen deprivation, is well recognized $[15,21]$ and the resultant metabolic acidemia, especially in the already hypoxemic neonate, may be the most important single element in the morbidity and mortality in these children [9, 11, 17]. Oxygen consumptions, however, were not determined in any of our patients during the study period.

A third possibility, an increase in free fatty acids secondary to the lipolytic action of these amines, might act to worsen the acidosis even further [27]. Information regarding free fatty acid levels in cyanotic children has, to our knowledge, not been reported and determinations were not performed in any of the children in this study.

Asphyxia and anoxia are known to produce striking increases in the secretion of $\mathrm{E}$ and $\mathrm{NE}$ in the experimental animal [10, 28]. Hypoxemic infants and children and those with congestive heart failure have been shown to have elevation of circulating as well as excreted catecholamines. Thus, Cheek and associates [6] found increases of $E$ in the blood of newborns who were hypoxemic with the respiratory distress syndrome, and Lees [20] has reported elevation of $\mathrm{MN}$ in the urine of his patients with cyanotic forms of congenital heart disease as well as the patients whom he studied who had congestive heart failure. The evidence from these previous studies suggests that these stressful situations may regularly elevate endogenous secretion of the studied amines in the neonate as well as in older children. The present study indicates that the chronic hypoxemia produced by cyanotic forms of congenital heart abnormalities may also act as a stimulus for the increased secretion of DA, E, and NE, as measured by their excretion in urine and that of their metabolites.

\section{Summary}

Studies of catecholamine excretion in urine were carried out on two groups of subjects. A control group consisted of 23 patients who were either considered normal with no pathologic condition whatsoever or as having a physical abnormality but without any condition known to stimulate catecholamine secretion. A second group of infants and children was selected consisting of 25 individuals having cyanotic congenital heart malformations. These children were similar to the control group in age.
Excretion in urine of E, NE, DA, VMA, and MN + NMN per 24 hr was studied. Although the cyanotic subjects as a group tended to have elevated excretion values for all the substances which were tested, only DA and MN + NMN showed statistically significant differences.

The results suggest that hypoxemia may cause increased secretion, as measured by excretion, of the catecholamines. The possible effects of increased catecholamine levels in subjects hypoxemic because of congenital cardiac defects may be significant, resulting in reduction of pulmonary blood flow and the development of metabolic acidemia.

\section{References and Notes}

1. Armstrong, M. D., Shaw, K. N. F., and Wall, P. E.: The phenolic acids of human urine. Paper chromatography of phenolic acids. J. Biol. Chem., 218: 293 (1956).

2. Axelrod, J.: Methylation reactions in the formation and metabolism of catecholamines and other biogenic amines. Pharmacol. Rev., 18: 95 (1966).

3. Axelrod, J., Inscoe, J. K., Senoh, S., And Wirkop, B.: Omethylation, the principal pathway for the metabolism of epinephrine and norepinephrine in the rat. Biochim. Biophys. Acta, 27: 210 (1958).

4. Braunwald, E., And Ebert, P. A.: Hemodynamic alterations idiopathic hypertrophic subaortic stenosis induced by sympathomimetic drugs. Amer. J. Cardiol., 10: 489 (1962).

5. Carlsson, A., and Waldeck, B.: A fluorimetric method for the determination of dopamine (3-hydroxytyramine). Acta Physiol. Scand., 44: 293 (1958).

6. Cheek, D. B., Malinek, M., and Fraillon, J. M.: Plasma adrenaline and noradrenaline in the neonatal period, and infants with respiratory distress syndrome and placental insufficiency. Pediatrics, 31: 374 (1963).

7. Cherian, G., Brockington, I. F., Shah, P. M., Oakley, C. M., AND GoodwIN, J. F.: Beta-adrenergic blockade in hypertrophic obstructive cardiomyopathy. Brit. Med. J., 1: 895 (1966).

8. Eriksson, B. O., Thoren, C., ANd ZetTerquist, P.: Long-term treatment with propranolol in selected cases of Fallot's tetralogy. Brit. Heart J., 31: 37 (1969).

9. Folger, G. M., Jr.: Unpublished data.

10. Goldfien, A., Ganong, W. F., And Wise, B.: Specific neural stimulation of norepinephrine secretion by the adrenal medulla during anoxia. J. Clin. Invest., 40: 1043 (1961).

11. Gootman, N. L., Scarpellr, E. M., ANd Rudolph, A. M.: Metabolic acidosis in children with severe cyanotic congenital heart disease. Pediatrics, 31: 251 (1963).

12. Harrison, D. C., Braunwald, E., Glick, G., Mason, D. T., Chidsey, C. A., AND Ross, J., JR.: Effects of beta adrenergic blockade on the circulation with particular reference to observations in patients with hypertrophic subaortic stenosis. Circulation, 29: 84 (1964).

13. Holmes, J. C., And Fowler, N. O.: Direct cardiac effects of dopamine. Circ. Res., 10: 68 (1962).

14. Honey, M., Chamberlain, D. A., and Howard, J.: The effect of beta-sympathetic blockade on arterial oxygen saturation in Fallot's tetralogy. Circulation, 30: 501 (1964). 
15. Huckabee, W. E.: Relationships of pyruvate and lactate during anaerobic metabolism. III. Effect of breathing lowoxygen gases. J. Clin. Invest., 37: 264 (1958).

16. Johnson, A. M.: Norepinephrine and cyanotic attacks in Fallot's tetralogy. Brit. Heart J., 23: 197 (1961).

17. Kamath, V. R., AND Jones, R. S.: Acid-base abnormalities in infants with congenital heart disease. Brit. Med. J., 2: 434 (1966).

18. Kopin, I. J., Herting, G., ANd Gordon, E. K.: Fate of norepinephrine- $\mathrm{H}^{3}$ in the isolated perfused heart. J. Pharmacol. Exp. Ther., 138: 34 (1962).

19. Krakoff, L. R., de Champlayn, J., and Axelrod, J.: Abnormal storage of norepinephrine in experimental hypertension in the rat. Circ. Res., 21: 583 (1967).

20. LEES, M. H.: Catecholamine metabolite excretion of infants with heart failure. J. Pediat., 69: 259 (1966).

21. Lundholm, L., Mohme-Lundholm, E., ANd Svedmyr, N.: Second Symposium on Catecholamines. Physiological relationships. Introductory remarks. Pharmacol. Rev., 18: 255 (1966).

22. Mason, D. T., Braunwald, E., and Ross, J., Jr.: Haemodynamic alterations induced by isoprenaline in patients with obstruction to right ventricular outflow. Brit. Heart J., 27: 884 (1965).

23. Maxwell, G. M., Rowe, G. G., Castillo, C. A., Clufford, J. E., Afonso, S., ANd CRumpton, C. W.: The effect of dopamine (3-hydroxytyramine), upon the systemic, pulmonary and cardiac haemodynamics and metabolism of intact dog. Arch. Int. Pharmacodyn. Ther., 129: 62 (1960).

24. Pisano, J. J.: A simple analysis for normetanephrine and metanephrine in urine. Clin. Chim. Acta, 5: 406 (1960).

25. Pisano, J. J., Crout, J. R., and Abraham, D.: Determina- tion of 3-methoxy-4-hydroxymandelic acid in urine. Clin. Chim. Acta, 7: 285 (1962).

26. Pletscher, A.: Monoamine oxidase inhibitors. Pharmacol. Rev., 18: 121 (1966).

27. Steingerg, D.: Catecholamine stimulation of fat mobilization and its metabolic consequences. Pharmacol. Rev., 18: 217 (1966).

28. VoGT, M.: Epinephrine and norepinephrine. In: H. N. Antonaides: Hormones in Human Plasma, p. 581. (Little, Brown, Boston, 1960).

29. Von Euler, U. S., ANd Floding, I.: Diagnosis of pheochromocytoma by fluorimetric estimation of adrenaline and noradrenaline in urine. Scand. J. Clin. Lab. Invest., 8: 288 (1956).

30. Voorhess, M. L.: Urinary catecholamine excretion by healthy children. I. Daily excretion of dopamine, norepinephrine, epinephrine and 3-methoxy-4-hydroxymandelic acid. Pediatrics, 39: 252 (1967).

31. Williams, C. M., Babuscio, A. A., and Watson, R.: In vivo alteration of the pathways of dopamine metabolism. Amer. J. Physiol., 199: 722 (1960).

32. Wurtman, R. J.: Catecholamines. New Engl. J. Med., 273: $746(1965)$

33. G. K. Turner Associates, Inc., Palo Alto, Calif.

34. Presented to The American Heart Association, Forty-third Scientific Session, Atlantic City, N. J., November 12-15, 1970.

35. Dr. Hollowell's present address is: Department of Pediatrics, Kansas University Medical Center, Kansas City, Kan.

36. Supported by Georgia Heart Association Grant no. 2T1HE5442-09.

37. Requests for reprints should be addressed to: GoRDon M. FolGER, JR., M.D., Section of Pediatric Cardiology, Henry Ford Hospital, Detroit, Mich. 48202 (USA).

38. Accepted for publication June 15, 1971. 